\title{
Impact of Indoor Physical Environment on Learning Efficiency in Different Types of Tasks: A $3 \times 4 \times 3$ Full Factorial Design Analysis
}

\author{
Lilin Xiong ${ }^{1,2}$, Xiao Huang ${ }^{3}$, Jie Li ${ }^{4}$, Peng Mao ${ }^{5}$, Xiang Wang ${ }^{5}$, Rubing Wang ${ }^{5}$ \\ and Meng Tang $1,6, *$ \\ 1 School of Public Health, Southeast University, Nanjing 210003, China; hzxionglilin@163.com \\ 2 Department of Environmental Health, Nanjing Municipal Center for Disease Control and Prevention, \\ Nanjing 210003, China \\ 3 Department of Hygiene, School of Public Health, Xiangnan University, Chenzhou 423000, China; \\ huangxiao1998@163.com \\ 4 School of Civil Engineering, Shenzhen University, Shenzhen 518060, China; 15250986656@163.com \\ 5 Department of Construction Management, School of Civil Engineering, Nanjing Forestry University, \\ Nanjing 210037, China; shadowsmyth@163.com (P.M.); yzwx97@163.com (X.W.); \\ wangrubinghappy@163.com (R.W.) \\ 6 Jiangsu Key Laboratory for Biomaterials and Devices, Southeast University, Nanjing 210009, China \\ * Correspondence: tm@seu.edu.cn; Tel.: +86-025-8327-2564
}

Received: 6 April 2018; Accepted: 10 June 2018; Published: 13 June 2018

\begin{abstract}
Indoor physical environments appear to influence learning efficiency nowadays. For improvement in learning efficiency, environmental scenarios need to be designed when occupants engage in different learning tasks. However, how learning efficiency is affected by indoor physical environment based on task types are still not well understood. The present study aims to explore the impacts of three physical environmental factors (i.e., temperature, noise, and illuminance) on learning efficiency according to different types of tasks, including perception, memory, problem-solving, and attention-oriented tasks. A $3 \times 4 \times 3$ full factorial design experiment was employed in a university classroom with 10 subjects recruited. Environmental scenarios were generated based on different levels of temperature $\left(17^{\circ} \mathrm{C}, 22^{\circ} \mathrm{C}\right.$, and $\left.27^{\circ} \mathrm{C}\right)$, noise $(40 \mathrm{~dB}(\mathrm{~A}), 50 \mathrm{~dB}(\mathrm{~A}), 60 \mathrm{~dB}(\mathrm{~A})$, and $70 \mathrm{~dB}(\mathrm{~A}))$ and illuminance (60 lx, $300 \mathrm{~lx}$, and $2200 \mathrm{~lx})$. Accuracy rate (AC), reaction time (RT), and the final performance indicator (PI) were used to quantify learning efficiency. The results showed ambient temperature, noise, and illuminance exerted significant main effect on learning efficiency based on four task types. Significant concurrent effects of the three factors on final learning efficiency was found in all tasks except problem-solving-oriented task. The optimal environmental scenarios for top learning efficiency were further identified under different environmental interactions. The highest learning efficiency came in thermoneutral, relatively quiet, and bright conditions in perception-oriented task. Subjects performed best under warm, relatively quiet, and moderately light exposure when recalling images in the memory-oriented task. Learning efficiency peaked to maxima in thermoneutral, fairly quiet, and moderately light environment in problem-solving process while in cool, fairly quiet and bright environment with regard to attention-oriented task. The study provides guidance for building users to conduct effective environmental intervention with simultaneous controls of ambient temperature, noise, and illuminance. It contributes to creating the most suitable indoor physical environment for improving occupants learning efficiency according to different task types. The findings could further supplement the present indoor environment-related standards or norms with providing empirical reference on environmental interactions.
\end{abstract}


Keywords: learning efficiency; task type; indoor physical environment; environmental factor; full factorial design

\section{Introduction}

The prevalence of sick building syndrome (SBS) symptoms leads to increasing concern about indoor environment in these days, because occupants spend most of their time learning or working indoors [1-4]. It was researched that indoor physical environment was significantly correlated to office work productivity $[2,5,6]$. A comfortable physical environment may stimulate work efficiency or help occupants remain productivity while environmental discomfort may result in negative productivity [7-9]. Effects of physical learning environment especially on cognitive load can be regarded as a determinant of the effectiveness of instruction [10]. In reviewing prior literature, temperature, noise, and illuminance are found the most common factors which influence occupant task performance or learning efficiency. For instance, Lan et al. (2011) investigated the effects of thermal discomfort on health as well as the performance of tasks simulating office work, and found that the subjects took lower work performance while warm $\left(30^{\circ} \mathrm{C}\right)$ than in thermoneutral condition $\left(22^{\circ} \mathrm{C}\right)$ [11]. To some extent, this is consistent with Seppanen and Fisk's (2005) research, which revealed that work performance might be improved within the room air temperature of $20 \sim 23^{\circ} \mathrm{C}$ [12]. Imhof (2014) showed that distracting and irrelevant sound interfered with information processing efficiency, which was in line with other findings [13-16]. Impact of stimulus background illumination seems to be another variable that influences visual perception, cognitive processing, and behavioral responses [17,18].

To our best knowledge, there was some empirical support for interactions of physical environmental factors on human comfort or task performance [19-21]. Most of the papers focused on the combinations between temperature and illuminance, followed by those between temperature and noise [22-25], but the research on how learning efficiency is affected by the concurrent multitude of ambient factors is still limited. Although there was support for interactions among noise, heat, and illuminance on cognitive performance [26], which interactive environmental scenario where the performance comes to the top was still not well understood. Besides, occupants always engage in different learning or working tasks indoors, most of which are related to perceptual processing, memory processing, problem-solving, or attentional focusing [21,27]. It appears that there may be fairly obvious disparities among learning efficiency in different tasks if ambient temperature, noise, and illuminance affected it simultaneously. However, there is little published work finding such environmental combined effect on learning efficiency based on task types. It is envisaged that the optimized physical environment should be created depending on both environmental interactions and learning tasks, but relevant information is currently unavailable.

We hypothesized that the indoor physical environmental factors, viz. temperature, noise, and illuminance, exerted significant main effect and concurrent effect on learning efficiency according to task types, and different interactive environments could be found when the efficiency peaked to maxima in different tasks. The objective of this study is to explore the impacts of indoor physical ambient factors including temperature, noise, and illuminance and their interactions on learning efficiency (viz. accuracy rate (AC), reaction time (RT), and performance indicator (PI)) in different types of learning tasks (i.e., perception, memory, problem-solving, and attention-oriented tasks). Furthermore, it aims to identify the optimal interactive environments where the highest learning efficiency achieved in different types of tasks with considering simultaneous effects of three factors. The paper provides guidance for building users to conduct effective environmental intervention by controlling environment indoors. It puts emphasis on creating the optimal physical environment indoors, with considering concurrent effect of the multitude of ambient factors, to help occupants achieve the highest learning efficiency in different types of tasks. Moreover, it provides a reference 
regarding environmental interactions for the present indoor environment-related standards or norms, which is conductive to promoting the human-centered design of buildings further.

\section{Material and Methods}

\subsection{Environmental Design}

The full factorial experiment was carried out in an environment-controlled university classroom $(11.7 \mathrm{~m} \times 9.0 \mathrm{~m} \times 3.0 \mathrm{~m})$, which had been used for more than five years. Ten individual desks were previously arranged in five rows in the center of it. Natural light indoors was provided through single-sided windows, over which were hung the movable shade curtains. A complete design led to 36 scenarios, with three main environmental factors including temperature at three levels, noise at four levels, and illuminance at three levels. Design for environmental scenarios in the $3 \times 4 \times 3$ full factorial experiment is shown in Table 1. Criteria for factor levels selected are illustrated.

Table 1. Design for environmental scenarios in $3 \times 4 \times 3$ full factorial experiment. ${ }^{\text {a }}$

\begin{tabular}{|c|c|c|c|c|c|c|c|c|c|}
\hline & \multicolumn{3}{|c|}{$T_{1}$} & \multicolumn{3}{|c|}{$T_{2}$} & \multicolumn{3}{|c|}{$\mathrm{T}_{3}$} \\
\hline & $\mathbf{I}_{\mathbf{1}}$ & $\mathbf{I}_{2}$ & $\mathbf{I}_{3}$ & $\mathbf{I}_{1}$ & $\mathrm{I}_{2}$ & $I_{3}$ & $\mathbf{I}_{1}$ & $\mathbf{I}_{2}$ & $\mathbf{I}_{3}$ \\
\hline $\mathrm{N}_{1}$ & $\mathrm{~T}_{1} \mathrm{~N}_{1} \mathrm{I}_{1}$ & $\mathrm{~T}_{1} \mathrm{~N}_{1} \mathrm{I}_{2}$ & $\mathrm{~T}_{1} \mathrm{~N}_{1} \mathrm{I}_{3}$ & $\mathrm{~T}_{2} \mathrm{~N}_{1} \mathrm{I}_{1}$ & $\mathrm{~T}_{2} \mathrm{~N}_{1} \mathrm{I}_{2}$ & $\mathrm{~T}_{2} \mathrm{~N}_{1} \mathrm{I}_{3}$ & $\mathrm{~T}_{3} \mathrm{~N}_{1} \mathrm{I}_{1}$ & $\mathrm{~T}_{3} \mathrm{~N}_{1} \mathrm{I}_{2}$ & $\mathrm{~T}_{3} \mathrm{~N}_{1} \mathrm{I}_{3}$ \\
\hline $\mathbf{N}_{2}$ & $\mathrm{~T}_{1} \mathrm{~N}_{2} \mathrm{I}_{1}$ & $\mathrm{~T}_{1} \mathrm{~N}_{2} \mathrm{I}_{2}$ & $\mathrm{~T}_{1} \mathrm{~N}_{2} \mathrm{I}_{3}$ & $\mathrm{~T}_{2} \mathrm{~N}_{2} \mathrm{I}_{1}$ & $\mathrm{~T}_{2} \mathrm{~N}_{2} \mathrm{I}_{2}$ & $\mathrm{~T}_{2} \mathrm{~N}_{2} \mathrm{I}_{3}$ & $\mathrm{~T}_{3} \mathrm{~N}_{2} \mathrm{I}_{1}$ & $\mathrm{~T}_{3} \mathrm{~N}_{2} \mathrm{I}_{2}$ & $\mathrm{~T}_{3} \mathrm{~N}_{2} \mathrm{I}_{3}$ \\
\hline $\mathbf{N}_{3}$ & $\mathrm{~T}_{1} \mathrm{~N}_{3} \mathrm{I}_{1}$ & $\mathrm{~T}_{1} \mathrm{~N}_{3} \mathrm{I}_{2}$ & $\mathrm{~T}_{1} \mathrm{~N}_{1} \mathrm{I}_{3}$ & $\mathrm{~T}_{2} \mathrm{~N}_{3} \mathrm{I}_{1}$ & $\mathrm{~T}_{2} \mathrm{~N}_{3} \mathrm{I}_{2}$ & $\mathrm{~T}_{2} \mathrm{~N}_{3} \mathrm{I}_{3}$ & $\mathrm{~T}_{3} \mathrm{~N}_{3} \mathrm{I}_{1}$ & $\mathrm{~T}_{3} \mathrm{~N}_{3} \mathrm{I}_{2}$ & $\mathrm{~T}_{3} \mathrm{~N}_{3} \mathrm{I}_{3}$ \\
\hline $\mathrm{N}_{4}$ & $\mathrm{~T}_{1} \mathrm{~N}_{4} \mathrm{I}_{1}$ & $\mathrm{~T}_{1} \mathrm{~N}_{4} \mathrm{I}_{2}$ & $\mathrm{~T}_{1} \mathrm{~N}_{4} \mathrm{I}_{3}$ & $\mathrm{~T}_{2} \mathrm{~N}_{4} \mathrm{I}_{1}$ & $\mathrm{~T}_{2} \mathrm{~N}_{4} \mathrm{I}_{2}$ & $\mathrm{~T}_{2} \mathrm{~N}_{4} \mathrm{I}_{3}$ & $\mathrm{~T}_{3} \mathrm{~N}_{4} \mathrm{I}_{1}$ & $\mathrm{~T}_{3} \mathrm{~N}_{4} \mathrm{I}_{2}$ & $\mathrm{~T}_{3} \mathrm{~N}_{4} \mathrm{I}_{3}$ \\
\hline
\end{tabular}

a $\mathrm{T}_{\mathrm{i}}$-temperature levels, in which, $\mathrm{T}_{1}$ represents $17^{\circ} \mathrm{C}, \mathrm{T}_{2}$ represents $22^{\circ} \mathrm{C}$, and $\mathrm{T}_{3}$ represents $27^{\circ} \mathrm{C} . \mathrm{N}_{\mathrm{i}}$-noise levels, in which $\mathrm{N}_{1}$ represents $40 \mathrm{~dB}(\mathrm{~A}), \mathrm{N}_{2}$ represents $50 \mathrm{~dB}(\mathrm{~A}), \mathrm{N}_{3}$ represents $60 \mathrm{~dB}(\mathrm{~A})$, and $\mathrm{N}_{4}$ represents $70 \mathrm{~dB}(\mathrm{~A})$. $\mathrm{I}_{\mathrm{i}}$-illuminance levels, in which, $\mathrm{I}_{1}$ represents 60 lx, $\mathrm{I}_{2}$ represents $300 \mathrm{~lx}$, and $\mathrm{I}_{3}$ represents $2200 \mathrm{~lx}$.

Limited to the experiment conducted in October and November in 2016, the temperature indoors was maintained at three intended levels of $17^{\circ} \mathrm{C}, 22^{\circ} \mathrm{C}$, and $27^{\circ} \mathrm{C}$ by controlling central air-conditionings. These temperature levels, ranging from moderately cool to moderately warm, were identified within the acceptable range of indoor temperatures in such a season after a pilot study. Simultaneously, they were within the operative range set by air-conditionings, bringing much convenience to create different environmental conditions. The lowest temperature, $17^{\circ} \mathrm{C}$, represented the moderately cool exposure found in the pilot study while the highest temperature, $27{ }^{\circ} \mathrm{C}$, represented the moderately warm exposure. The temperature of $22{ }^{\circ} \mathrm{C}$, at the mid-point of the intended range, was selected because it was considered to create a condition for optimal performance [28]. Temperatures were measured using a U.S. Gray Wolf indoor air detector (GrayWolf Sensing Solutions, LLC, Shelton, CT, USA). Three kinds of thermal environments were defined according to the actual measurements, including cool environment $\left(17.32 \pm 0.47^{\circ} \mathrm{C}\right)$, thermoneutral environment $\left(22.21 \pm 0.63^{\circ} \mathrm{C}\right)$, and warm environment $\left(27.11 \pm 0.68^{\circ} \mathrm{C}\right)$.

Noises indoors are found in a pilot study that they are commonly composed of talking noises, air-conditioning noises, distant outside car horns, and even shoes clattering. It is therefore the noise distractor in experiments was previously recorded in the classroom to simulate the actual acoustic environment for daily in-class learning. Ambient noise in the experimental classroom was $40 \mathrm{~dB}(\mathrm{~A})$ when it was unoccupied, similar to the acoustic condition in daily ones. $50-80 \mathrm{~dB}(\mathrm{~A})$ were estimated by Mackenzie as typical of indoor noises [29], but it was only measured with occasional peaks to $80 \mathrm{~dB}(\mathrm{~A})$ in the pilot study. Therefore, the noises of $40 \mathrm{~dB}(\mathrm{~A}), 50 \mathrm{~dB}(\mathrm{~A}), 60 \mathrm{~dB}(\mathrm{~A})$, and $70 \mathrm{~dB}(\mathrm{~A})$ were finally selected as variables in actual experiments. To ensure the noise levels as homogeneous as possible inside, they were controlled by four multimedia players which were positioned in four separate corners. A noise dosimeter, model AWA5610D (Hangzhou Aihua Instruments Co. Ltd., Hangzhou, China), was used for measurement. During the experiments, all the windows and doors were closed to minimize external distractions. There were four different acoustic environments finally identified: fairly quiet environment $(40.85 \mathrm{~dB}(\mathrm{~A}) \pm 0.43 \mathrm{~dB}(\mathrm{~A}))$, relatively quiet environment (51.73 dB(A) $\pm 0.55 \mathrm{~dB}(\mathrm{~A}))$, relatively noisy environment (61.83 dB(A) $\pm 1.20 \mathrm{~dB}(\mathrm{~A}))$, and fairly noisy environment (72.32 dB(A) $\pm 0.74 \mathrm{~dB}(\mathrm{~A}))$. 
Natural illuminance was measured indoors on a sunny day in the pilot study (no fluorescent lights turned on). Three levels were employed at 50-70 lx, 200-400 lx, and 2000-2400 lx according to distance from single-sided windows. For better variable controls, mid-points of these three ranges, $60 \mathrm{~lx}, 300 \mathrm{~lx}$, and 2200 lx, were finally selected based on Standards for Lighting Design of Buildings (GB50034-2013) and the previous research work [30]. $60 \mathrm{~lx}$ is lower than the minimum standard for indoor lighting (100 lx), $300 \mathrm{~lx}$ is the recommended illuminance for libraries or classrooms, and $2200 \mathrm{~lx}$ far exceeds indoor illuminance comfort levels. Lighting environment in experiments was mainly created by natural light. Curtains were closed for shading when the illuminance indoors was further higher than what was needed. Diminutive cool-white trichromatic lamps were additionally arranged on the top left corner of each desk for ideal illuminance controls. To make the illuminance as homogenous as possible all around the subjects, lamps were designed adjustable. Therefore, illuminance on desks could be controlled flexibly based on the actual measurement. All the lamps were previously tested to avoid risks of spontaneous uncontrollable flicker. Illuminance was measured using an illumination photometer, model TES-1332A (TES Electrical Electronic Corp., Taibei, China), with three lighting scenarios differently classified, i.e., dark environment ( $61.55 \pm 1.79 \mathrm{~lx})$, moderately light environment $(319.75 \pm 13.89 \mathrm{~lx})$, and bright environment $(2202.14 \pm 22.21 \mathrm{~lx})$. Experiments started only if the illuminance on all desks met experiment requirements.

All instruments were calibrated before each experiment. Layouts of measurement on temperature, noise and illuminance were designed according to Methods of Health Monitoring for Public Places (GB/T 18204.1-2013), especially the section regarding physical factors. All other physical environmental factors were held at a fixed level controlled by central air-conditionings, and thus, they could be kept relatively constant in the whole experimental course. The series of experiments lasted 36 days in total, with one scenario per day in the sequence that is previously set on basis of level changes of each factor. All scenarios experimented were independent with each other.

\subsection{Subjects}

Subjects were required to participate in the whole course of the experiment with everyone attending all 36 environmental scenarios. Considering the long experiment period, 10 college students (five males and five females) aged between 20 and 24 years old were recruited as voluntary subjects from a previous large-scale ground survey based on the following criteria: non-smokers or alcoholics, absence of diseases, and normal or corrected-to-normal version. All subjects recruited were required to have more than three years of local experience to avoid the effects of environmental inadaptability [31,32]. The information was obtained from questionnaires distributed during the recruitment survey. Besides, none of them was examined medically.

To minimize individual differences, the subjects were required to receive enough sleep and a regular diet and keep emotional stability in experiment period. Activities probably causing experimental bias were also limited as follows. Drugs were not allowed on experimental days. Alcohol could not be consumed within 12 hours before each exposure. Teas or other drinks that function as stimulating nerves and cardiovascular systems were not allowed within eight hours before each exposure. Strenuous exercises were also not allowed within three hours before each exposure, which helped stabilize blood sugar and avoid neural hyper excitability. Subjects were instructed to wear long-sleeved cotton T-shirts, long trousers, long underclothes on the top and bottom, socks, and shoes (1.0 clo), corresponding to the typical clothing indoors based on local climates. To avoid distractions from subjective evaluations on indoor physical environments, environmental variables designed were introduced to subjects using blind intervention approach.

\subsection{Learning Tasks}

Occupants mainly engage in brainwork through a series of cognitive activities regarding information processing (receiving, explaining, organizing, and extracting) in essence [33]. Cognition, as the whole processing cycle of information, can be divided into four main categories including perception, memory, 
problem-solving performance, and attention [8]. According to the characteristics of brainwork and cognition, cognitive capacity can be roughly regarded as an indicator of learning efficiency. Therefore, on basis of reliability, validity, difficulty, and discriminability separately, four classical tests representing each category of cognitions were selected from both domestic and international achievements in the existing psychological domain, and were conducted to measure the efficiency of different types of learning tasks in this study (Table 2). Detailed information about each task is following.

Table 2. Tests on learning efficiency in different types of tasks.

\begin{tabular}{cc}
\hline Task Type & Test \\
\hline Perception-oriented task & The Rochester color word test \\
Memory-oriented task & Recognition of meaningless images \\
Problem-solving-oriented task & Reading comprehension \\
Attention-oriented task & Number searching test \\
\hline
\end{tabular}

\subsubsection{Perception-Oriented Task}

The Rochester color word test was conducted to test the capacity of virtual perception [34]. A total of 15 words of colors in another color were presented on papers. Subjects were asked to pick out the word itself or its color sequentially.

\subsubsection{Memory-Oriented Task}

Recognition of meaningless images was conducted to test capacity for short-term memory [35]. A total of 10 meaningless images on paper were presented for only $10 \mathrm{~s}$. When time was up, the subjects were asked to pick them out from all 20 meaningless images on another paper as quickly as possible.

\subsubsection{Problem-Solving-Oriented Task}

Reading comprehension was conducted to test problem-solving performance [36]. Subjects were asked to pick out the only correct answer from multiple choices based on their own understandings. Previously printed out, five independent questions were randomly distributed to each subject from the administrative ability tasks for national civil servant selections.

\subsubsection{Attention-Oriented Task}

Number searching test was conducted to test attention [37-39]. Numbers 0 through 99 were sequenced out of order on papers. Subjects were asked to search 15 designated numbers in normal order from these 100 numbers.

The output of work is related to both quantity and quality. To evaluate learning efficiency in different tasks, accuracy rate (AC), reaction time (RT), and the final performance indicator (PI) were chosen as three dependent variables [8,36,40-42], where AC is the percentage of correct answers and RT is the time for which the task was completed, so that PI represents the overall rate correctly completed in each task. The relationship among them is as follows:

$$
\mathrm{PI}=\mathrm{AC} / \mathrm{RT}
$$

To simulate the most common routine performance, subjects were singly exposed without anyone under close supervision. The completion time of each task was recorded by subjects themselves while the percentage correct and the final PI were then calculated by research associates after experiments. During the week prior to the formal experiment, subjects were given one introduction session and two other training sessions to make themselves fully familiarized with the task procedure as well as the task rules, so that the potential deviations caused by different extent of familiarity with tasks was cautiously avoided. All answers should be given in pens. 
Each test lasted around 10 min without putting too much intellectual pressure on subjects. Besides, a five-minute break was set between each test with the next. Therefore, impact of fatigue in the long task duration could be ignored. Subjects were asked to arrive 10 min before the first task starting, in which, they were instructed to sit on their separate seats in a designated classroom and were only allowed to do some quiet activities such as reading, listening to music, and doing homework. Therefore, all 10 subjects exposed for around one hour at each time, starting at approx. 2.00 p.m. All tests conducted under every scenario were independent with each other without order effect. The experiment schedule is designed as shown in Figure 1, for much quality control and experimental efficiency in the whole process.

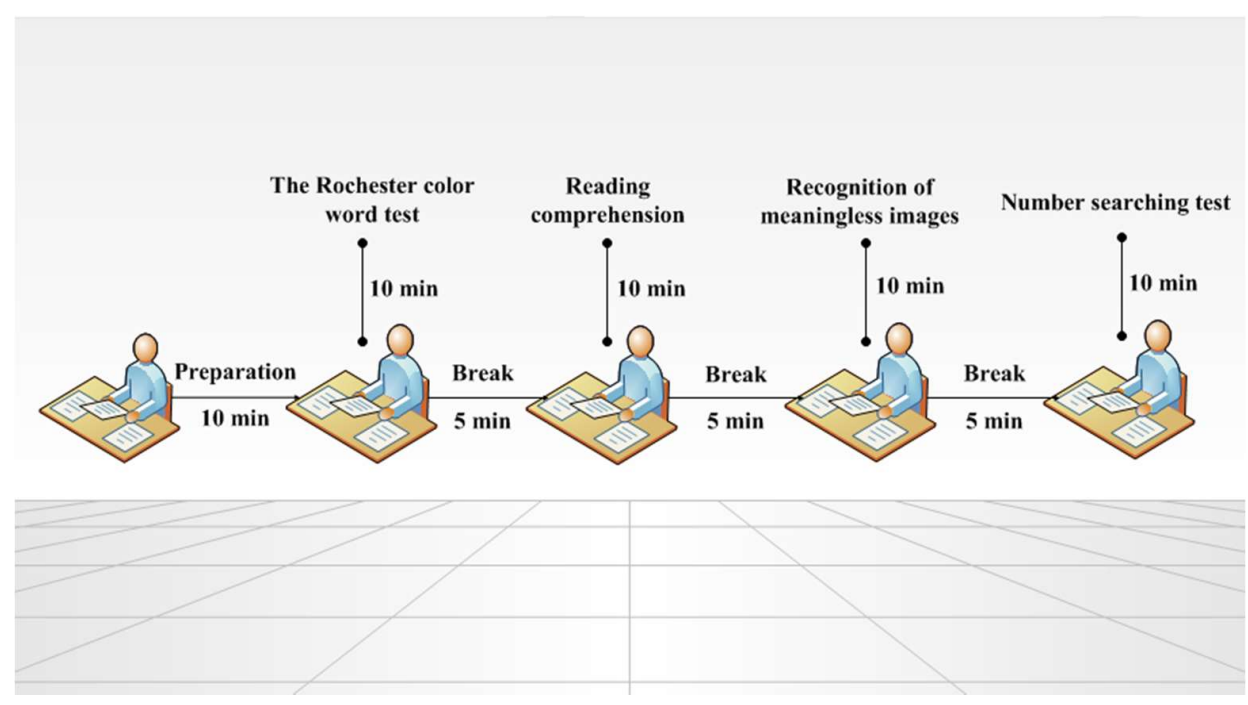

Figure 1. Experiment schedule in each environmental scenario.

\subsection{Data Analysis}

Factor levels of the physical indoor environment (i.e., temperature, noise, and illuminance) shown in mean \pm standard deviation (SD), were measured within their individual $95 \%$ confidence interval. MANOVA in full factorial model was then conducted to explore the main effects and interaction effects of the three environmental factors on learning efficiency in different tasks. Data collected was tested for normal distribution with using the Kolmogorov-Smirnov Test. Non-normal distributed data were computed with statistical disposal after a log-normal transformation. All analyses were performed using SPSS version 22.0 (IBM, Armonk, NY, USA). Significance was defined as $p<0.05$.

\section{Results}

\subsection{Main Effects of Indoor Physical Environment on Learning Efficiency in Different Tasks}

At the protected significance level, the main effect of temperature on AC was significant, which was found only in The Rochester color word test. That means no significance changed with respect to impact of temperature on perception $\mathrm{AC}$ when noise or illuminance increased or decreased. It seems temperature, noise, and illuminance failed to affect AC individually in three other tasks. We detected significant main effects of illuminance on RT and PI regarding visual perception (RT: $\mathrm{F}=13.306, p<0.05 ; \mathrm{PI}: \mathrm{F}=13.286, p<0.05$ ). It is shown that RT and PI across perception, which were individually influenced by illuminance, changed slightly as temperatures from $17{ }^{\circ} \mathrm{C}$ to $27^{\circ} \mathrm{C}$ and noise levels from $40 \mathrm{~dB}(\mathrm{~A})$ to $70 \mathrm{~dB}(\mathrm{~A})$. Therefore, for the perception-oriented task, temperature indoors was regarded as a dominant factor affecting $\mathrm{AC}$ while illuminance was another dominant factor that influenced both RT and PI. 
Revealed from the results, temperature, noise and illuminance failed to significantly affect AC in the memory-oriented task, the individual effect on $\mathrm{AC}$ among which was found to be sensitive to the two others $(p>0.05$, n.s.). On the contrary, there was significant main effect of each of these three factors on RT and PI in recognition of meaningless images $(p<0.05)$.

Both temperature and noise exerted significant main influence on RT in reading comprehension (temperature: $\mathrm{F}=5.207, p<0.05$; noise: $\mathrm{F}=14.855, p<0.05$ ), so did they on $\mathrm{RT}$ in number searching test (temperature: $\mathrm{F}=4.544, p<0.05$; noise: $\mathrm{F}=4.634, p<0.05$ ). That is to say, it was obvious that the time in which subjects reacted in the problem-solving-oriented and attention-oriented task changed, when indoor temperature or noise levels individually increased or decreased in the range experimented. According to the final performance of learning efficiency, however, the dominant environmental factors were quite different from each other in these two types of tasks. Significant main effects of noise and illuminance were observed on PI in problem-solving process $(\mathrm{F}=3.277, p<0.05)$, while significant main effect of temperature was only found regarding attention $(\mathrm{F}=10.197, p<0.05)$. Details of the main effects of indoor temperature, noise and illuminance on learning efficiency in these four tasks are depicted in Table 3.

Table 3. Main effects of indoor temperature, noise and illuminance on learning efficiency in different tasks.

\begin{tabular}{|c|c|c|c|c|c|c|c|}
\hline & & & DF & SS & MS & $\mathbf{F}$ & $p$ \\
\hline \multirow{9}{*}{ Perception-oriented task } & \multirow{3}{*}{$\mathrm{AC}^{\mathrm{a}}$} & Temperature & 2 & 266.485 & 133.242 & 3.329 & 0.037 * \\
\hline & & Noise & 3 & 140.617 & 46.872 & 1.171 & 0.321 \\
\hline & & Illuminance & 2 & 10.990 & 5.495 & 0.137 & 0.872 \\
\hline & \multirow{3}{*}{$\mathrm{RT}^{\mathrm{a}}$} & Temperature & 2 & 4332.198 & 2166.099 & 2.478 & 0.085 \\
\hline & & Noise & 3 & 6634.407 & 2211.469 & 2.530 & 0.057 \\
\hline & & Illuminance & 2 & $23,257.991$ & $11,628.996$ & 13.306 & $0.000 *$ \\
\hline & \multirow{3}{*}{$\mathrm{PI}^{\mathrm{a}}$} & Temperature & 2 & 0.116 & 0.058 & 2.742 & 0.066 \\
\hline & & Noise & 3 & 0.166 & 0.055 & 2.623 & 0.051 \\
\hline & & Illuminance & 2 & 0.561 & 0.280 & 13.286 & 0.000 * \\
\hline \multirow{9}{*}{ Memory-oriented task } & \multirow{3}{*}{$\mathrm{AC}^{\mathrm{a}}$} & Temperature & 2 & 143.889 & 71.944 & 0.376 & 0.687 \\
\hline & & Noise & 3 & 263.056 & 87.685 & 0.458 & 0.712 \\
\hline & & Illuminance & 2 & 27.222 & 13.611 & 0.071 & 0.931 \\
\hline & \multirow{3}{*}{$\mathrm{RT}^{\mathrm{a}}$} & Temperature & 2 & 503.439 & 251.719 & 4.144 & 0.017 * \\
\hline & & Noise & 3 & 1625.484 & 541.828 & 8.920 & $0.000 *$ \\
\hline & & Illuminance & 2 & 802.265 & 401.326 & 6.607 & $0.002 *$ \\
\hline & \multirow{3}{*}{$\mathrm{PI}^{\mathrm{a}}$} & Temperature & 2 & 9.205 & 4.603 & 3.905 & $0.021 *$ \\
\hline & & Noise & 3 & 19.891 & 6.630 & 5.626 & $0.001 *$ \\
\hline & & Illuminance & 2 & 13.999 & 6.999 & 5.939 & $0.003 *$ \\
\hline \multirow{9}{*}{ Problem-solving-oriented task } & \multirow{3}{*}{$\mathrm{AC}^{\mathrm{a}}$} & Temperature & 2 & 168.889 & 84.444 & 0.210 & 0.811 \\
\hline & & Noise & 3 & 2111.111 & 703.704 & 1.750 & 0.157 \\
\hline & & Illuminance & 2 & 1135.556 & 567.778 & 1.412 & 0.245 \\
\hline & \multirow{3}{*}{$\mathrm{RT}^{\mathrm{a}}$} & Temperature & 2 & $11,086.794$ & 5543.397 & 5.207 & $0.006^{*}$ \\
\hline & & Noise & 3 & $47,443.360$ & $15,814.453$ & 14.855 & 0.000 * \\
\hline & & Illuminance & 2 & 2820.614 & 1410.307 & 1.325 & 0.267 \\
\hline & \multirow{3}{*}{$\mathrm{PI}^{\mathrm{a}}$} & Temperature & 2 & 0.035 & 0.017 & 0.949 & 0.388 \\
\hline & & Noise & 3 & 0.540 & 0.180 & 9.870 & $0.000 *$ \\
\hline & & Illuminance & 2 & 0.120 & 0.060 & 3.277 & 0.039 * \\
\hline \multirow{9}{*}{ Attention-oriented task } & \multirow{3}{*}{$\mathrm{AC}^{\mathrm{a}}$} & Temperature & 2 & 1.645 & 0.823 & 0.160 & 0.852 \\
\hline & & Noise & 3 & 1.037 & 0.346 & 0.067 & 0.977 \\
\hline & & Illuminance & 2 & 3.196 & 1.598 & 0.311 & 0.733 \\
\hline & \multirow{3}{*}{$\mathrm{RT}^{\mathrm{a}}$} & Temperature & 2 & 4211.492 & 2105.746 & 4.544 & $0.011 *$ \\
\hline & & Noise & 3 & 6441.957 & 2147.319 & 4.634 & $0.003 *$ \\
\hline & & Illuminance & 2 & 122.755 & 61.378 & 0.132 & 0.876 \\
\hline & \multirow{3}{*}{$\mathrm{PI}^{\mathrm{a}}$} & Temperature & 2 & 6.188 & 3.094 & 10.197 & $0.000 *$ \\
\hline & & Noise & 3 & 2.042 & 0.675 & 2.224 & 0.085 \\
\hline & & Illuminance & 2 & 0.538 & 0.269 & 0.887 & 0.413 \\
\hline
\end{tabular}

* Difference is significant at the $p<0.05$ level (2-tailed). a AC-Accuracy Rate, RT-Reaction Time, PI-Performance Indicator. 


\subsection{Interaction Effects of Indoor Physical Environment on Learning Efficiency in Different Tasks}

As shown in Table 4, there are different interaction effects of indoor temperature, noise and illuminance on efficiency in four learning tasks. The Rochester color word test was the only experiment, in which AC was concurrently affected by all three ambient factors. Significant interactions between temperature and noise were found on AC across perception (AC: $\mathrm{F}=2.472, p<0.05$ ). However, it was detected in this task that the final PI was significantly influenced by noise interacting with illuminance instead of with temperature. Therefore, it should give priority to the simultaneous modulation between noise and illuminance for promoting the final perception performance. Moreover, we found perception-related RT was rather more sensitive to the multitude of environmental factors than AC and PI. There was more than one kind of significant environmental interactions on RT of perception, including the interaction between temperature and noise as well as that between noise and illuminance (temperature $\times$ noise: $\mathrm{F}=2.155, p<0.05$; noise $\times$ illuminance: $\mathrm{F}=2.623, p<0.05$ ).

There were the most combined effects found in recognition of meaningless images despite none being found for AC. The significant interaction effect between temperature and noise was shown on RT $(\mathrm{F}=4.703, p<0.05)$ and PI $(\mathrm{F}=3.888, p<0.05)$ for short-term recollection. Meanwhile, they were both interactively influenced by temperature, noise, and illuminance together with great significance (RT: $\mathrm{F}=3.165, p<0.05 ; \mathrm{PI}: \mathrm{F}=2.764, p<0.05$ ). Besides, it was found that RT across memory was significantly affected by the crossover between temperature and illuminance $(F=3.727$, $p<0.05)$. Hence, as for memory-oriented tasks, all three factors, such as ambient temperature, noise, and illuminance, should be comprehensively taken into account when learning zones need designing.

Learning efficiency in reading comprehension was not sensitive to the concurrent effects of environmental factors compared with others. RT was the single dependent variable reflecting obvious interactions in this task, which was only significantly detected between temperature and noise $(\mathrm{F}=4.511, p<0.05)$. No interaction effect was observed on AC and PI in reading comprehension $(p>0.05$, n.s.). It was thus illustrated that learning efficiency in problem solving process depends much on the individual main effects of ambient factors rather than their interactions.

Table 4. Interaction effects of indoor temperature, noise and illuminance on learning efficiency in different tasks.

\begin{tabular}{|c|c|c|c|c|c|c|c|}
\hline & & & DF & SS & MS & F & $p$ \\
\hline \multirow{12}{*}{ Perception-oriented task } & \multirow{4}{*}{$\mathrm{AC}^{\mathrm{a}}$} & Temperature $\times$ Noise & 6 & 593.650 & 98.942 & 2.472 & 0.024 * \\
\hline & & Temperature $\times$ Illuminance & 4 & 159.008 & 39.752 & 0.993 & 0.411 \\
\hline & & Noise $\times$ Illuminance & 6 & 115.778 & 19.296 & 0.482 & 0.822 \\
\hline & & Temperature $\times$ Noise $\times$ Illuminance & 12 & 556.346 & 46.362 & 1.158 & 0.312 \\
\hline & \multirow{4}{*}{$\mathrm{RT}^{\mathrm{a}}$} & Temperature $\times$ Noise & 6 & $11,300.046$ & 1883.341 & 2.155 & 0.047 * \\
\hline & & Temperature $\times$ Illuminance & 4 & 1878.833 & 469.708 & 0.537 & 0.708 \\
\hline & & Noise $\times$ Illuminance & 6 & $13,754.610$ & 2292.435 & 2.623 & $0.017^{*}$ \\
\hline & & Temperature $\times$ Noise $\times$ Illuminance & 12 & $12,794.923$ & 1066.244 & 1.220 & 0.268 \\
\hline & \multirow{4}{*}{$\mathrm{PI}^{\mathrm{a}}$} & Temperature $\times$ Noise & 6 & 0.265 & 0.044 & 2.089 & 0.054 \\
\hline & & Temperature $\times$ Illuminance & 4 & 0.080 & 0.020 & 0.949 & 0.436 \\
\hline & & Noise $\times$ Illuminance & 6 & 0.300 & 0.050 & 2.370 & 0.030 * \\
\hline & & Temperature $\times$ Noise $\times$ Illuminance & 12 & 0.387 & 0.032 & 1.528 & 0.113 \\
\hline \multirow{12}{*}{ Memory-oriented task } & \multirow{4}{*}{$\mathrm{AC}^{\mathrm{a}}$} & Temperature $\times$ Noise & 6 & 909.444 & 151.574 & 0.791 & 0.577 \\
\hline & & Temperature $\times$ Illuminance & 4 & 427.778 & 106.944 & 0.558 & 0.693 \\
\hline & & Noise $\times$ Illuminance & 6 & 312.778 & 52.130 & 0.272 & 0.950 \\
\hline & & Temperature $\times$ Noise $\times$ Illuminance & 12 & 352.222 & 29.352 & 0.153 & 1.000 \\
\hline & \multirow{4}{*}{$\mathrm{RT}^{\mathrm{a}}$} & Temperature $\times$ Noise & 6 & 1714.152 & 285.692 & 4.703 & 0.000 * \\
\hline & & Temperature $\times$ Illuminance & 4 & 905.583 & 226.396 & 3.727 & 0.006 * \\
\hline & & Noise $\times$ Illuminance & 6 & 541.087 & 90.181 & 1.485 & 0.183 \\
\hline & & Temperature $\times$ Noise $\times$ Illuminance & 12 & 2307.325 & 192.277 & 3.165 & 0.000 * \\
\hline & \multirow{4}{*}{$\mathrm{PI}^{\mathrm{a}}$} & Temperature $\times$ Noise & 6 & 27.491 & 4.582 & 3.888 & 0.001 * \\
\hline & & Temperature $\times$ Illuminance & 4 & 7.639 & 1.910 & 1.620 & 0.169 \\
\hline & & Noise $\times$ Illuminance & 6 & 10.209 & 1.702 & 1.444 & 0.197 \\
\hline & & Temperature $\times$ Noise $\times$ Illuminance & 12 & 39.091 & 3.258 & 2.764 & 0.001 * \\
\hline \multirow{4}{*}{$\begin{array}{l}\text { Problem-solving-oriented } \\
\text { task }\end{array}$} & \multirow{4}{*}{$\mathrm{AC}^{\mathrm{a}}$} & Temperature $\times$ Noise & 6 & 328.889 & 54.815 & 0.136 & 0.991 \\
\hline & & Temperature $\times$ Illuminance & 4 & 917.778 & 229.444 & 0.570 & 0.684 \\
\hline & & Noise $\times$ Illuminance & 6 & 1628.889 & 271.481 & 0.675 & 0.670 \\
\hline & & Temperature $\times$ Noise $\times$ Illuminance & 12 & 3011.111 & 250.926 & 0.624 & 0.822 \\
\hline
\end{tabular}


Table 4. Cont.

\begin{tabular}{|c|c|c|c|c|c|c|c|}
\hline & & & DF & SS & MS & $\mathbf{F}$ & $p$ \\
\hline \multirow{8}{*}{$\begin{array}{l}\text { Problem-solving-oriented } \\
\text { task }\end{array}$} & \multirow{4}{*}{$\mathrm{RT}^{\mathrm{a}}$} & Temperature $\times$ Noise & 6 & $29,068.415$ & 4844.736 & 4.551 & $0.000 *$ \\
\hline & & Temperature $\times$ Illuminance & 4 & 3051.334 & 762.834 & 0.717 & 0.581 \\
\hline & & Noise $\times$ Illuminance & 6 & 8474.340 & 1412.390 & 1.327 & 0.245 \\
\hline & & Temperature $\times$ Noise $\times$ Illuminance & 12 & $18,005.647$ & 1500.471 & 1.409 & 0.160 \\
\hline & \multirow{4}{*}{$\mathrm{PI}^{\mathrm{a}}$} & Temperature $\times$ Noise & 6 & 0.142 & 0.024 & 1.292 & 0.260 \\
\hline & & Temperature $\times$ Illuminance & 4 & 0.046 & 0.012 & 0.635 & 0.638 \\
\hline & & Noise $\times$ Illuminance & 6 & 0.141 & 0.024 & 1.291 & 0.261 \\
\hline & & Temperature $\times$ Noise $\times$ Illuminance & 12 & 0.370 & 0.031 & 1.687 & 0.068 \\
\hline \multirow{12}{*}{ Attention-oriented task } & \multirow{4}{*}{$A C^{a}$} & Temperature $\times$ Noise & 6 & 22.273 & 3.712 & 0.721 & 0.633 \\
\hline & & Temperature $\times$ Illuminance & 4 & 38.863 & 9.716 & 1.888 & 0.112 \\
\hline & & Noise $\times$ Illuminance & 6 & 15.226 & 2.538 & 0.493 & 0.813 \\
\hline & & Temperature $\times$ Noise $\times$ Illuminance & 12 & 46.285 & 3.857 & 0.750 & 0.702 \\
\hline & \multirow{4}{*}{$\mathrm{RT}^{\mathrm{a}}$} & Temperature $\times$ Noise & 6 & 5646.301 & 941.050 & 2.031 & 0.061 \\
\hline & & Temperature $\times$ Illuminance & 4 & 1854.149 & 463.537 & 1.000 & 0.408 \\
\hline & & Noise $\times$ Illuminance & 6 & 7081.988 & 1180.331 & 2.547 & $0.020 *$ \\
\hline & & Temperature $\times$ Noise $\times$ Illuminance & 12 & $10,469.745$ & 872.479 & 1.883 & $0.036^{*}$ \\
\hline & \multirow{4}{*}{$\mathrm{PI}^{\mathrm{a}}$} & Temperature $\times$ Noise & 6 & 4.163 & 0.694 & 2.287 & $0.035 *$ \\
\hline & & Temperature $\times$ Illuminance & 4 & 0.430 & 0.107 & 0.354 & 0.841 \\
\hline & & Noise $\times$ Illuminance & 6 & 3.988 & 0.665 & 2.191 & 0.044 * \\
\hline & & Temperature $\times$ Noise $\times$ Illuminance & 12 & 5.196 & 0.433 & 1.427 & 0.152 \\
\hline
\end{tabular}

As for the attention-oriented task, combined effect between noise and illuminance was indicated significantly modulating both RT $(\mathrm{F}=2.547, p<0.05)$ and PI $(\mathrm{F}=2.191, p<0.05)$. Besides, two more interactive scenarios were separately found in this task. RT was also significantly altered by interactions of the multitude of all three environmental factors $(\mathrm{F}=1.883, p<0.05)$ while PI was significantly affected by temperature and noise $(\mathrm{F}=2.287, p<0.05)$. There was still no significant interaction shown on $\mathrm{AC}$ in the number searching test $(p>0.05$, n.s.).

\subsection{Optimal Environmental Scenarios in Different Types of Learning Tasks}

As PI reflects the final performance with considering both quality and quantity of learning output, the optimal environmental scenarios where the highest learning efficiency was achieved in different tasks were finally identified according to it. Table 5 illustrates results of the final PI on basis of task types among 36 full factorial designs.

There were clear disparities among the most suitable thermal conditions for efficiency, which were affected by the simultaneous temperature, noise and illuminance in different tasks. Subjects gained the peak level of learning efficiency with regards to perception and problem-solving-oriented tasks in the thermoneutral environment. Differently, cool exposure provoked the highest efficiency in the attention-oriented task while warm exposure worked regarding recollection.

Fairly noisy exposure $(70 \mathrm{~dB}(\mathrm{~A}))$ interacted with ambient temperature and illuminance was commonly found leading to the lowest efficiency in different tasks. On the contrary, a quieter environment was more suitable for cognitive activities in each kind of tasks. The acoustic environment, however, was not equal to the noise of zero level. It was illustrated that learning efficiency commonly peaked at maxima when there was less than $50 \mathrm{~dB}(\mathrm{~A})$, and a stricter acoustic environment was required in the problem-solving-oriented and attention-oriented task than in the other two tasks.

Influenced by temperature and noise concurrently, the highest learning efficiency was achieved mostly in lighting exposure of no less than $300 \mathrm{~lx}$, the illuminance level in general indoor environmental-related standards or norms. Specifically, perception or attention-oriented tasks usually depended on bright condition interacting with temperature and noise, with the highest performance appearing on level of $2200 \mathrm{~lx}$. The optimal environmental scenarios based on task types are depicted in detail, shown in Table 5. 
Table 5. Mean \pm Standard Deviation (SD) for task PI (Performance Indicator) under different environmental scenarios.

\begin{tabular}{|c|c|c|c|c|c|c|c|c|c|c|}
\hline \multirow{6}{*}{ Perception-oriented task } & & \multicolumn{3}{|c|}{$17^{\circ} \mathrm{C}$} & \multicolumn{3}{|c|}{$22{ }^{\circ} \mathrm{C}$} & \multicolumn{3}{|c|}{$27^{\circ} \mathrm{C}$} \\
\hline & & $601 x$ & $300 \mathrm{~lx}$ & $22001 x$ & $601 x$ & $300 \mathrm{~lx}$ & $22001 x$ & $601 x$ & $300 \mathrm{~lx}$ & $22001 x$ \\
\hline & $40 \mathrm{~dB}(\mathrm{~A})$ & $0.78 \pm 0.12$ & $0.66 \pm 0.13$ & $0.68 \pm 0.12$ & $0.65 \pm 0.14$ & $0.76 \pm 0.13$ & $0.79 \pm 0.21$ & $0.64 \pm 0.17$ & $0.63 \pm 0.11$ & $0.55 \pm 0.12^{b}$ \\
\hline & $50 \mathrm{~dB}(\mathrm{~A})$ & $0.62 \pm 0.16$ & $0.69 \pm 0.11$ & $0.75 \pm 0.15$ & $0.60 \pm 0.12$ & $0.67 \pm 0.16$ & $0.81 \pm 0.21^{\mathrm{a}}$ & $0.63 \pm 0.21$ & $0.63 \pm 0.08$ & $0.76 \pm 0.13$ \\
\hline & $60 \mathrm{~dB}(\mathrm{~A})$ & $0.68 \pm 0.18$ & $0.64 \pm 0.11$ & $0.70 \pm 0.13$ & $0.70 \pm 0.16$ & $0.66 \pm 0.13$ & $0.72 \pm 0.17$ & $0.58 \pm 0.06$ & $0.64 \pm 0.16$ & $0.80 \pm 0.16$ \\
\hline & $70 \mathrm{~dB}(\mathrm{~A})$ & $0.63 \pm 0.13$ & $0.60 \pm 0.08$ & $0.79 \pm 0.16$ & $0.56 \pm 0.08$ & $0.59 \pm 0.20$ & $0.64 \pm 0.18$ & $0.56 \pm 0.10$ & $0.62 \pm 0.12$ & $0.72 \pm 0.16$ \\
\hline \multirow{6}{*}{ Memory-oriented task } & & \multicolumn{3}{|c|}{$17^{\circ} \mathrm{C}$} & \multicolumn{3}{|c|}{$22{ }^{\circ} \mathrm{C}$} & \multicolumn{3}{|c|}{$27^{\circ} \mathrm{C}$} \\
\hline & & $601 x$ & $3001 x$ & $22001 x$ & $601 x$ & $300 \mathrm{~lx}$ & $22001 x$ & $601 x$ & $3001 x$ & $22001 x$ \\
\hline & $40 \mathrm{~dB}(\mathrm{~A})$ & $3.68 \pm 1.09$ & $2.77 \pm 0.64$ & $4.00 \pm 1.91$ & $3.38 \pm 0.86$ & $3.74 \pm 1.10$ & $3.83 \pm 1.19$ & $2.51 \pm 0.80$ & $3.61 \pm 1.11$ & $2.40 \pm 0.64$ \\
\hline & $50 \mathrm{~dB}(\mathrm{~A})$ & $3.60 \pm 1.25$ & $3.39 \pm 0.93$ & $3.03 \pm 1.04$ & $2.68 \pm 0.60$ & $3.04 \pm 1.27$ & $4.04 \pm 1.43$ & $2.61 \pm 0.94$ & $4.08 \pm 1.36^{\mathrm{a}}$ & $4.07 \pm 1.79$ \\
\hline & $60 \mathrm{~dB}(\mathrm{~A})$ & $3.40 \pm 1.60$ & $3.57 \pm 1.19$ & $2.88 \pm 0.88$ & $2.25 \pm 0.42$ & $3.08 \pm 0.86$ & $2.70 \pm 0.89$ & $3.11 \pm 0.95$ & $3.12 \pm 1.20$ & $3.50 \pm 0.84$ \\
\hline & $70 \mathrm{~dB}(\mathrm{~A})$ & $2.78 \pm 0.71$ & $3.06 \pm 1.16$ & $3.96 \pm 1.83$ & $2.17 \pm 0.60^{b}$ & $2.28 \pm 0.50$ & $2.22 \pm 0.56$ & $2.50 \pm 0.73$ & $2.41 \pm 0.84$ & $3.79 \pm 1.09$ \\
\hline \multirow{6}{*}{ Problem-solving-oriented task } & & \multicolumn{3}{|c|}{$17^{\circ} \mathrm{C}$} & \multicolumn{3}{|c|}{$22{ }^{\circ} \mathrm{C}$} & \multicolumn{3}{|c|}{$27^{\circ} \mathrm{C}$} \\
\hline & & $601 x$ & $300 \mathrm{~lx}$ & $22001 x$ & $601 x$ & $3001 x$ & $22001 x$ & $601 x$ & $3001 x$ & $22001 x$ \\
\hline & $40 \mathrm{~dB}(\mathrm{~A})$ & $0.51 \pm 0.13$ & $0.39 \pm 0.10$ & $0.50 \pm 0.21$ & $0.46 \pm 0.11$ & $0.52 \pm 0.20^{\mathrm{a}}$ & $0.46 \pm 0.17$ & $0.41 \pm 0.11$ & $0.48 \pm 0.14$ & $0.38 \pm 0.15$ \\
\hline & $50 \mathrm{~dB}(\mathrm{~A})$ & $0.42 \pm 0.13$ & $0.47 \pm 0.11$ & $0.47 \pm 0.17$ & $0.44 \pm 0.13$ & $0.40 \pm 0.10$ & $0.49 \pm 0.16$ & $0.39 \pm 0.15$ & $0.49 \pm 0.13$ & $0.47 \pm 0.19$ \\
\hline & $60 \mathrm{~dB}(\mathrm{~A})$ & $0.38 \pm 0.12$ & $0.42 \pm 0.11$ & $0.36 \pm 0.14$ & $0.32 \pm 0.14$ & $0.44 \pm 0.14$ & $0.33 \pm 0.15$ & $0.32 \pm 0.11$ & $0.38 \pm 0.09$ & $0.49 \pm 0.14$ \\
\hline & $70 \mathrm{~dB}(\mathrm{~A})$ & $0.36 \pm 0.10$ & $0.39 \pm 0.09$ & $0.47 \pm 0.13$ & $0.30 \pm 0.11^{\mathrm{b}}$ & $0.33 \pm 0.13$ & $0.35 \pm 0.14$ & $0.38 \pm 0.13$ & $0.32 \pm 0.08$ & $0.45 \pm 0.13$ \\
\hline \multirow{6}{*}{ Attention-oriented task } & & \multicolumn{3}{|c|}{$17^{\circ} \mathrm{C}$} & \multicolumn{3}{|c|}{$22{ }^{\circ} \mathrm{C}$} & \multicolumn{3}{|c|}{$27^{\circ} \mathrm{C}$} \\
\hline & & $601 x$ & $3001 x$ & $22001 x$ & $601 x$ & $300 \mathrm{~lx}$ & $22001 x$ & $601 x$ & $3001 x$ & $22001 x$ \\
\hline & $40 \mathrm{~dB}(\mathrm{~A})$ & $1.69 \pm 0.69$ & $1.38 \pm 0.42$ & $2.13 \pm 1.02^{\mathrm{a}}$ & $1.50 \pm 0.28$ & $1.65 \pm 0.65$ & $1.68 \pm 0.57$ & $1.30 \pm 0.19$ & $1.37 \pm 0.24$ & $1.34 \pm 0.37$ \\
\hline & $50 \mathrm{~dB}(\mathrm{~A})$ & $1.42 \pm 0.39$ & $1.62 \pm 0.60$ & $1.72 \pm 1.11$ & $1.21 \pm 0.22$ & $1.26 \pm 0.27$ & $1.59 \pm 2.37$ & $1.68 \pm 0.84$ & $1.50 \pm 0.31$ & $1.51 \pm 0.26$ \\
\hline & $60 \mathrm{~dB}(\mathrm{~A})$ & $1.77 \pm 0.94$ & $1.74 \pm 0.51$ & $1.03 \pm 0.27^{b}$ & $1.22 \pm 0.38$ & $1.40 \pm 0.37$ & $1.17 \pm 0.25$ & $1.40 \pm 0.48$ & $1.39 \pm 0.39$ & $1.42 \pm 0.25$ \\
\hline & $70 \mathrm{~dB}(\mathrm{~A})$ & $1.71 \pm 0.98$ & $1.52 \pm 0.41$ & $1.95 \pm 1.38$ & $1.18 \pm 0.17$ & $1.06 \pm 0.12$ & $1.11 \pm 0.13$ & $1.40 \pm 0.38$ & $1.06 \pm 0.19$ & $1.43 \pm 0.23$ \\
\hline
\end{tabular}

${ }^{a}$ The highest PI achieved in each type of task. ${ }^{\mathrm{b}}$ The lowest PI achieved in each type of task. 


\section{Discussion}

Different combinations of environmental factors have been researched for improving work or learning performance in prior studies [19-21]. However, they mostly failed to give strong evidence for the simultaneous combined impact of physical environmental environment on learning efficiency according to types of tasks. To our best knowledge, this is a study which makes up for lack of the available information on how multiple physical environmental factors including temperature, noise, and illuminance, affect learning efficiency indoors concurrently in different kinds of learning tasks (viz. perception, memory, problem-solving, and attention-oriented tasks) from a cognitive perspective of the whole informational processing cycle.

Consistent with previous studies [8,36,40-42], we observed the final performance indicator (PI), which reflects the combined learning efficiency was significantly influenced by different levels of temperature, noise, and illuminance. Hence, the optimal scenarios where the highest PI was achieved in four different tasks, are further discussed based on their main or interacted effects in the current study.

Interactions on perception were found between visual and thermal environments $[43,44]$. The focus in this research is on the visual perception, an integration of objective reality that directly reflects on human sensory organs, among which, eyes are considered to be the most important bridge for information input [45-47]. It differs from superior cognition processes like reading comprehension or attention [46]. Therefore, the perception-oriented task highly stresses the eye-hand coordination in practical settings. According to physiological theory and cognitive psychological theory, up to $80 \%$ of the information received from outside is processed by the visual pathway, and color is regarded as the primary visual language [48]. This is because the visual stimulation from light is much stronger and more direct than functions of other external physical media [8]. Hence illuminance, which showed the exclusive main effect in this task, could be regarded as the primary factor for perceptual efficiency. As the illuminance level increased from 60 lx to 2200 lx, the PI level of the subjects correspondingly increased in the range experimented. There were also significant interactions between light and noise conditions with regard to the perception-oriented task. This accords with the earlier observations, which demonstrated interactions on self-assessed work suitability between light and noise in simulated office [49]. If an interaction is present, arousal, affect, or activation might concurrently contribute to their plausibility as mediators of cognition $[50,51]$. In the perception-oriented task, the perceptual processing to maxima was detected in the thermoneutral, relatively quiet and bright environment. It seems possible that bright-light exposure with mild temperature leads the subjects to high arousal and high activation when visual sensation is simulated. Supported by Tham's (2004) study in the tropics, office workers were activated in a slightly cool work environment within the range of $20-24^{\circ} \mathrm{C}$, in which they felt more energetic [52]. Besides, in another experiment to explore interactions between noise and illuminance on perception, subjects were self-reported to perform better under low intelligibility noise based on their activated pleasure [53]. Therefore, the finding in the perception-oriented task is consistent with the arousal theory that the optimum level of performance for easy tasks shows in the region of high arousal $[54,55]$, which could be found in earlier findings.

As for memory-oriented tasks, different environmental interactions on memory performance may be attributed to disparities among the targets to memorize. Hygge and Knez (2001) found the significant crossover interactions between noise and temperature on the recall of the text but those between noise and light on the free recall of the emotionally toned words [23]. Whereas in the present research, the final PI on meaningless images recognition was significantly affected by concurrent temperature, noise and illuminance indoors. Similar to RAM in PC, short term memory refers to the ability to store temporary information in the brain, the limit of which ought to be acknowledged that it is susceptible when the information is reserved or processed. At the same time, ambient interference is quite disruptive to human memory with respect to visually presented items [56]. Therefore, the recall of images seems to be more sensitive than that of text or tuned words to temperature, noise, and illuminance surroundings, leading to a much more sophisticated combined effect. The highest efficiency for recollection was achieved in warm, relatively quiet, and moderately 
light environments. In other words, when warm air with a bit of noise was needed in moderate-lighting exposure, the ability to store and process temporary information was much more promoted in human brain. Findings that impaired recall with heat at the high noise level but improved recall at the low noise level were illustrated in the current research, which is not in accordance with the prior result of noise increasing arousal or activation, and mild heat decreasing it [23]. Hence, it is likely that the noise increasing arousal model was not thoroughly suitable for the memory-oriented task. Increased activation on recollection efficiency caused by lower noise levels in warm and moderately lighting condition, the finding of which corroborates to the earlier theoretical conjecture to some extent, showing that ambient factors might act directly on cognitive performance without any arousal, affect or activation as mediators [57]. Furthermore, the optimal environment regarding memory in this study is some inconsistent with that in the research of Park et al. (2013), who found a higher illuminance level (700 lx) was more beneficial to the efficacy of short term memory than the low one because it significantly helped alleviate mental load in retention period [58]. However, the factorial design in their experiment only focused on the effect of illumination condition on memory without temperature or noise into account. Thus, it could be illustrated from ours that the increased illuminance level was counteracted by low noise with heat and moderate light.

Subjects achieved the highest learning efficiency under thermoneutral and moderate-lighting exposure with the lowest noise in the problem-solving-oriented task. However, none significant combined effect on problem-solving efficiency was found among ambient temperature, noise and illuminance indoors, which was quite contrary to our previous hypothesis that interactions could be significantly found in each type of task. Therefore, in terms of environmental controls in learning zones where much brainwork is needed, main effect rather than interactions of ambient factors could be primarily emphasized for efficiency. Noise is suggested as a dominant factor due to its individual main effect. As the noise level increased from $40 \mathrm{~dB}(\mathrm{~A})$ to $70 \mathrm{~dB}(\mathrm{~A})$, the final PI level of the subjects adversely decreased in the range experimented. The reason is probably that when noise levels are raised, people's central neutral systems are easily stimulated by surroundings, leading to a decline in their cognitive functions $[59,60]$. Compared with the perception and memory-oriented tasks, the requirements for an acoustic environment were stricter in regards to critical thinking. This is because in the problem solving process, thinking could be an indirect reaction that the brain conducts for objectives, which is superior to a direct perceptual or retention period. Illuminance is another ambient factor that illustrates the significant main effect on problem-solving efficiency. Although the trend shows that as the illuminance level increased from $60 \mathrm{~lx}$ to $2200 \mathrm{~lx}$, the PI level increased, it does not seem clear. If there were small disparities of learning efficiency under the illuminance of $300 \mathrm{~lx}$ and $2200 \mathrm{~lx}$, the former level should be recommended from the energy-saving perspective, which is confirmed by the present findings that $300 \mathrm{~lx}$ was an illuminance level for optimal environmental efficiency in the problem-solving task.

As another aspect reflecting cognitive performance, attention refers to the ability against ambient interference when disturbed by irrelevant information. Interactions between noise and temperature found in our study could be supplemented by conclusions in the previous research that noise did not interact with heat in attention tasks [61]. This is because the levels of noise $(72 \mathrm{~dB}, 80 \mathrm{~dB}$, and $90 \mathrm{~dB})$ and temperature $\left(22.7 \sim 34.4^{\circ} \mathrm{C}\right)$ selected might not quite simulate an actual indoor environment. According to the main and combined effect in this attention-oriented task, it was known the trend that as temperature increased, the final PI decreased was significantly affected by changing noise. At the high level of illuminance, the efficiency achieved in the environment simultaneously affected by noise and temperature was higher than that in one affected by temperature or noise individually. It could be therefore speculated that there was a synergetic interaction between noise $(40 \mathrm{~dB}(\mathrm{~A})$, $50 \mathrm{~dB}(\mathrm{~A}), 60 \mathrm{~dB}(\mathrm{~A}), 70 \mathrm{~dB}(\mathrm{~A}))$ and temperature $\left(17^{\circ} \mathrm{C}, 22^{\circ} \mathrm{C}, 27^{\circ} \mathrm{C}\right)$ on attention. Additionally, the observed changes in PI provides evidence that bright exposure could modulate our attention with regard to interactions with temperature and noise. It seems that the increment in illuminance levels was assumed to increase arousal. The finding in Kaida's (2012) study confirmed that humans often experienced bright illumination conditions which may increase cognitive performance [59]. As cool 
and bright exposure brought high arousal, the potential drowsiness due to fairly quiet conditions could be naturally counteracted. This is why the subjects were the most concentrated in a cool, fairly quiet and bright environment in the attention-oriented task. Only if each fixation is aimed instead of in the process of eye saccade does attention occur. It is where the perceptual span appears, the range of valuable information precisely captured under each gaze in cognitive process [62,63]. Visually perceptual span is also called sensory memory, in which information will not be admitted to the next stage of short term memory until paid attention to. Hence the design requirement for indoor physical environment where the highest learning efficiency peaked in attention-oriented task would be quite different from that in memory-oriented task.

Currently, the standard of "PD ISO/TR 15742-Ergonomics of the physical environmentCombined effects of thermal environment, air pollution, acoustics and illumination on humans" has been developed, but it is still at the ideas stage [25]. Simultaneously, ASHRAE Guideline 10P also puts emphasis on interactions among indoor environmental factors, in which most studies only investigated impact of one or two factors correlated to human comfort without considering what interaction effect the multitude of ambient factors may exert on learning efficiency from perspective of objective performance in cognitive processes [44]. They also do not identify the optimal environmental scenario for efficiency in different types of learning tasks. If the knowledge regarding environmental interactions could be incorporated in the indoor environment-related standards or norms, human-centered design of buildings should be further promoted. A deeper comprehension of interactions of indoor physical environmental factors would lead to a better understanding of their combined effect on learning efficiency according to types of tasks, which better helps efficient environmental intervention to create the optimal learning environment for the highest occupant efficiency.

To investigate the detailed interaction effect of indoor physical environment on learning efficiency according to different task types, a full factorial design experiment was carried out in the current study but there were some limitations. Regarding the long experimental period lasting 36 days, the experiment failed to take female response into consideration [64-66]. Sex-related differences will be considered in further cross-designed research to explore more details on interactions and crossovers in gender, with the existing physical environmental factors. Besides, the sample size was limited due to the complexity of experimental design. A larger size of samples will be selected in the following experiments. Our future work will focus on a comprehensive indoor environmental point of view with more multiple ambient factors taken into consideration to testify and expand the present research findings further.

\section{Conclusions}

Our observations provide substantial evidence that indoor physical environmental factors, including temperature, noise, and illuminance exerted significant main effects on learning efficiency in perception, memory, problem-solving, and attention-oriented tasks. There was a significant concurrent effect of three factors on learning efficiency, considering the final PI in four types of tasks except the problem-solving-oriented task. The optimal environmental scenarios where the top task learning efficiency was achieved were then identified based on PI under different interactions of ambient temperature, noise and illuminance. The highest efficiency came in thermoneutral, relatively quiet, and bright conditions with respect to the perception-oriented task. Subjects performed best under warm, relatively quiet, and moderate light exposure when recalling images. Learning efficiency of subjects peaked to maxima in thermoneutral, fairly quiet, and moderately light environments in problem-solving processes, while in cool, fairly quiet, and bright environment in the attention-oriented task. The findings in this research helps building users better understand the concurrent effect of ambient factors as well as facilitate indoor physical environments more efficiently for learning efficiency improvement. It could also supplement the present indoor environment-related standards or norms with providing an empirical reference on environmental interactions. More positive impact of the multitude of environmental factors will be accentuated in the future work. 
Author Contributions: L.X. and P.M. conceived and designed the experiments. L.X., X.H. and M.T. contributed experimental instruments, materials, and analysis tools. X.H., J.L. and P.M. analyzed data and interpreted data. J.L. and P.M. wrote this manuscript. L.X., X.H. and M.T. edited this manuscript. X.W. and R.W. checked data and designed tables and figures in this research.

Acknowledgments: This work was supported by the National Natural Science Foundation of China (Grant No. 31671034, 81473003, 81673218, 81573186, 81302461, 81502783), the National Important Project on Scientific Research of China (Project Code: 2011CB933404), the Medical Technology Development Program Foundation of Nanjing (Project Code: ZKX16068), and Fundamental Research Funds for the Central Universities \& Research and Innovation Program for Graduate Students in Universities of Jiangsu Province (SJZZ16_0033). Special thanks to all the volunteers for their participation and cooperation in the research.

Conflicts of Interest: The authors declare no conflict of interest.

\section{References}

1. Kosonen, R.; Tan, F. The effect of perceived indoor air quality on productivity loss. Energy Build. 2004, 36, 981-986. [CrossRef]

2. Wargocki, P.; Wyon, D.P.; Sundell, J.; Clausen, G.; Fanger, P.O. The effects of outdoor air supply rate in an office on perceived air quality, sick building syndrome (SBS) symptoms and productivity. Indoor Air 2000, 10, 222-236. [CrossRef] [PubMed]

3. Park, J.S.; Yoon, C.H. The effects of outdoor air supply rate on work performance during 8-h work period. Indoor Air 2011, 21, 284-290. [CrossRef] [PubMed]

4. Saari, A.; Tissari, T.; Valkama, E.; Seppänen, O. The effect of a redesigned floor plan, occupant density and the quality of indoor climate on the cost of space, productivity and sick leave in an office building-A case study. Build. Environ. 2006, 41, 1961-1972. [CrossRef]

5. Horr, Y.A.; Arif, M.; Kaushik, A.; Mazroei, A.; Katafygiotou, M.; Elsarrag, E. Occupant productivity and office indoor environment quality: A review of the literature. Build. Environ. 2016, 105, 369-389. [CrossRef]

6. Wargocki, P.; Wyon, D.P.; Yong, K.B.; Clausen, G.; Fanger, P.O. Perceived air quality, sick building syndrome (SBS) symptoms and productivity in an office with two different pollution loads. Indoor Air 1999, 9, 165-179. [CrossRef] [PubMed]

7. Hioki, T.; Masuda, K.; Isobe, H. Study for quantitive evaluation methods with the aim of comfortable environment and improvement of working efficiency for work area. Symp. Environ. Eng. 2004, 77-80. [CrossRef]

8. Lan, L. The Influence Mechanism of Indoor Environment on Personnel Working Efficiency and Evaluation Study. Ph.D. Thesis, Shanghai Jiao Tong University, Shanghai, China, 2010. (In Chinese)

9. Manning, M.; Manning, G. How comfortable is your classroom? Teaching reading and writing. Teach. Pre K-8 1993, 24, 127-128.

10. Choi, H.H.; Merriënboer, J.J.G.V.; Paas, F. Effects of the physical environment on cognitive load and learning: Towards a new model of cognitive load. Educ. Psychol. Rev. 2014, 26, 225-244. [CrossRef]

11. Lan, L.; Wargocki, P.; Wyon, D.P.; Lian, Z. Effects of thermal discomfort in an office on perceived air quality, SBS symptoms, physiological responses, and human performance. Indoor Air 2011, 21, 376-390. [CrossRef] [PubMed]

12. Seppã Nen, O.; Fisk, W. Some quantitative relations between Indoor environmental quality and work performance or health. HVACER Res. 2006, 12, 957-973.

13. Imhof, M.; Välikoski, T.R.; Laukkanen, A.M.; Kai, O. Cognition and interpersonal communication: The effect of voice quality on information processing and person perception. Stud. Commun. Sci. 2014, 14, 37-44. [CrossRef]

14. Larsen, J.D.; Baddeley, A. Disruption of verbal STM by irrelevant speech, articulatory suppression, and manual tapping: Do they have a common source? Q. J. Exp. Psychol. 2003, 56, 1249-1268. [CrossRef] [PubMed]

15. Klatte, M.; Meis, M.; Sukowski, H.; Schick, A. Effects of irrelevant speech and traffic noise on speech perception and cognitive performance in elementary school children. Noise Health 2007, 9, 64-74. [CrossRef] [PubMed]

16. Farley, L.A.; Neath, I.; Allbritton, D.W.; Surprenant, A.M. Irrelevant speech effects and sequence learning. Mem. Cognit. 2007, 35, 156-165. [CrossRef] [PubMed]

17. Nakamura, H.; Karasawa, Y. Relationship between illuminance/color temperature and preference of atmosphere. J. Light Vis. Environ. 1999, 23, 29-38. [CrossRef] 
18. Noguchi, H.; Sakaguchi, T. Effect of illuminance and color temperature on lowering of physiological activity. Appl. Hum. Sci. 1999, 18, 117-123. [CrossRef]

19. Tiller, D.; Wang, L.M.; Musser, A.; Radik, M.J. Combined effects of noise and temperature on human comfort and performance. ASHRAE Trans. 2010, 116, 522-540.

20. Pellerin, N.; Candas, V. Combined effects of temperature and noise on human discomfort. Physiol. Behav. 2003, 78, 99-106. [CrossRef]

21. Witterseh, T.; Wyon, D.P.; Clausen, G. The effects of moderate heat stress and open-plan office noise distraction on SBS symptoms and on the performance of office work. Indoor Air 2004, 14 (Suppl. 8), 30-40. [CrossRef] [PubMed]

22. Hancock, P.A.; Pierce, J.O. Combined effects of heat and noise on human performance: A review. Am. Ind. Hygiene Assoc. J. 1985, 46, 555-566. [CrossRef] [PubMed]

23. Hygge, S. The interaction of noise and mild heat on cognitive performance and serial reaction time. Environ. Int. 1991, 17, 229-234. [CrossRef]

24. Veitch, J.A. Office noise and illumination effects on reading comprehension. Environ. Psychol. 1990, 10, 209-217. [CrossRef]

25. Torresin, S.; Pernigotto, G.; Cappelletti, F.; Gasparella, A. Combined effects of environmental factors on human perception and objective performance: A review of experimental laboratory works. Indoor Air 2018. [CrossRef] [PubMed]

26. Hygge, S.; Knez, I. Effects of noise, heat and indoor lighting on cognitive performance and self-reported affect. Environ. Psychol. 2001, 21, 291-299. [CrossRef]

27. Pan, Z.; Kjaergaard, S.K.; Mølhave, L.A. Chamber-experiment investigation of the interaction between perceptions of noise and odor in humans. Int. Arch. Occup. Environ. Health 2003, 76, 598-604. [CrossRef] [PubMed]

28. Seppanen, O.; Fisk, W.J.; Lei, Q.H. Room temperature and productivity in office work. Off. Sci. Tech. Inf. Tech. Rep. 2006, 1, 243-247.

29. Mackenzie, S.T. Noise and Office Work: Employee and Employer Concerns; State School of Industrial and Labor Relations: Ithaca, NY, USA, 1975.

30. Juslén, H.; Wouters, M.; Tenner, A. The influence of controllable task-lighting on productivity: A field study in a factory. Appl. Ergon. 2007, 38, 39-44. [CrossRef] [PubMed]

31. Luo, M.; Dear, R.D.; Ji, W.; Lin, B.; Ouyang, Q.; Zhu, Y. The dynamics of thermal comfort expectations. Build. Environ. 2015, 95, 322-329. [CrossRef]

32. Geng, Y.; Ji, W.; Lin, B.; Zhu, Y. The impact of thermal environment on occupant IEQ perception and productivity. Build. Environ. 2017, 121, 158-167. [CrossRef]

33. Parsons, P.; Sedig, K. Handbook of Human Centric Visualization; Springer: New York, NY, USA, 2014; pp. 693-715. ISBN 978-1-4614-7484-5.

34. Evans, G.W.; Johnson, D. Stress and open-office noise. J. Appl. Psychol. 2000, 85, 779-783. [CrossRef] [PubMed]

35. Zhu, Y. Experimental Psychology; Peking University Press: Beijing, China, 2014. (In Chinese)

36. Paul, W.L.; Taylor, P.A. A comparison of occupant comfort and satisfaction between a green building and a conventional building. Build. Environ. 2008, 43, 1858-1870. [CrossRef]

37. Wang, G.; Wang, A.S. Cognitive Psychology; Peking University Press: Beijing, China, 2001. (In Chinese)

38. Wilson, R.; Keil, F. The MIT Encyclopedia of the Cognitive Sciences; Shanghai Foreign Language Education Press: Shanghai, China, 2000; pp. 78-79.

39. Best, J.B. Cognitive Psychology; China Light Industry Press: Beijing, China, 2000.

40. Zhang, Y.M.; Zheng, J. Study on the Effect of Indoor Light Environment on Work Efficiency. Master's Thesis, School of Urban Construction and Environmental Engineering, Chongqing University, Chongqing, China, 2014. (In Chinese)

41. Wickens, C.D.; Hollands, J.G.; Parasuraman, R.; Banbury, S. Engineering Psychology E Human Performance; Abstracts of JSSX Meeting; Psychology Press: Hove, UK, 2012.

42. Luo, M.; Dear, R.D.; Ji, W.; Cao, B.; Lin, B.; Ouyang, Q.; Zhu, Y. The dynamics of thermal comfort expectations: The problem, challenge and implication. Build. Environ. 2016, 95, 231-241. [CrossRef]

43. Ishibashi, K.; Arikura, S.; Kozaki, T.; Higuchi, S.; Yasukouchi, A. Thermoregulatory effect in humans of suppressed endogenous melatonin by pre-sleep bright-light exposure in a cold environment. Chronobiol. Int. 2010, 27, 782-806. [CrossRef] [PubMed] 
44. Huang, L.; Zhu, Y.; Ouyang, Q.; Cao, B. A study on the effects of thermal, luminous, and acoustic environments on indoor environmental comfort in offices. Build. Environ. 2012, 49, 304-309. [CrossRef]

45. Putnam, A.L.; Sungkhasettee, V.W.; Rd, R.H. Optimizing learning in college: Tips from cognitive psychology. Perspect. Psychol. Sci. 2016, 11, 652-660. [CrossRef] [PubMed]

46. Solso, R.L. Cognitive psychology: Pearson new international edition. Eur. J. Epidemiol. 2008, 23, 411-422.

47. Gu, H.R. Study on the Processing Level of Visual Perception in Graphic Cognition Task. Master's Thesis, School of Psychology and Cognitive Science, East China Normal University, Shanghai, China, 2010. (In Chinese)

48. Haupt, C.; Huber, A.B. How axons see their way-Axonal guidance in the visual system. Front. Biosci. 2008, 13, 3136-3149. [CrossRef] [PubMed]

49. Yamazaki, K.; Nomoto, S.; Yokota, Y.; Murai, T. Effects of temperature, light, and sound on perceived work environment. ASHRAE Trans. 1998, 104 Pt 1A, 711-720.

50. Iordan, A.D.; Dolcos, F. Brain Activity and Network Interactions Linked to Valence-Related Differences in the Impact of Emotional Distraction. Cereb. Cortex 2015, 27, 731-749. [CrossRef] [PubMed]

51. Gorai, A.K.; Siddiqui, T.; Dey, U.K.; Singh, G. Combined effect of noise and illumination on worker performance. Noise Control Eng. J. 2007, 55, 417-424. [CrossRef]

52. Tham, K.W. Effects of temperature and outdoor air supply rate on the performance of call center operators in the tropics. Indoor Air 2004, 14 (Suppl. 7), 119-125. [CrossRef] [PubMed]

53. Liebl, A.; Haller, J.; Jödicke, B.; Baumgartner, H.; Schlittmeier, S.; Hellbrück, J. Combined effects of acoustic and visual distraction on cognitive performance and well-being. Appl. Ergon. 2012, 43, 424-434. [CrossRef] [PubMed]

54. Mcmaster, N. Behaviour modification with hypnotic visualisation, the mental side of golf: A case history. Aust. J. Clin. Hypnother. Hypn. 1993, 14, 17-22.

55. Temple, J.G.; Warm, J.S.; Dember, W.N.; Jones, K.S.; LaGrange, C.M.; Matthews, G. The effects of signal salience and caffeine on performance, workload, and stress in an abbreviated vigilance task. Hum. Factors 2000, 42, 183-194. [CrossRef] [PubMed]

56. Campbell, T.; Beaman, C.P.; Berry, D.C. Auditory memory and the irrelevant sound effect: Further evidence for changing-state disruption. Memory 2002, 10, 199-214. [CrossRef] [PubMed]

57. Smolders, K.C.H.J.; Kort, Y.A.W.D. Bright light and mental fatigue: Effects on alertness, vitality, performance and physiological arousal. J. Environ. Psychol. 2014, 39, 77-91. [CrossRef]

58. Park, J.Y.; Min, B.K.; Jung, Y.C.; Pak, H.; Jeong, Y.H.; Kim, E. Illumination influences working memory: An EEG study. Neuroscience 2013, 247, 386-394. [CrossRef] [PubMed]

59. Klatte, M.; Lachmann, T.; Schlittmeier, S.; Hellbrück, J. The irrelevant sound effect in short-term memory: Is there developmental change? Eur. J. Cognit. Psychol. 2010, 22, 1168-1191. [CrossRef]

60. Gan, Y.Q. Psychological and Behavioral Science Statistics; Peking University Press: Beijing, China, 2005; ISBN 9787301089743. (In Chinese)

61. Viteles, M.S.; Smith, K.R. An experimental investigation of the effect of change in atmospheric conditions and noise upon performance. Heat. Pip. Air Cond. 1946, 18, 107-112.

62. Shen, D.; Bai, X.; Yan, G.; Liversedge, S.P. The Perceptual Span in Chinese Reading; Psychology Press: Washington, DC, USA, 2009; pp. 255-276.

63. Guo, H.L.; Song, Z.M.; Zhang, Y.J. An eye movement study on the effect of news broadcast background on college students' reading efficiency. Psychol. Res. 2017, 10, 15-21.

64. Da Silva Carneiro, C.; de Almeida, A.A.F.; Ribas, A.; Kluk-De Kort, K.; Lima, D.O.; de Araújo, A.M.G.D.; de Holanda Ferreira, D.A.; Martins, M.L.; Freitas, T.M.M.W.C.; de Rosa, M.R.D. Hormones and Auditory Perception: Study of Dichotic Listening in Women during the Menstrual Cycle. Int. Arch. Otorhinolaryngol. 2018. [CrossRef]

65. Goldstein, J.; Sites, C.K.; Toth, M.J. Progesterone stimulates cardiac muscle protein synthesis via receptor-dependent pathway. Fertil. Steril. 2004, 82, 430-436. [CrossRef] [PubMed]

66. Gamberale, F.; Strindberg, L.; Wahlberg, I. Female work capacity during the menstrual cycle: Physiological and psychological reactions. Scand. J. Work Environ. Health 1975, 1, 120-127. [CrossRef] [PubMed]

(C) 2018 by the authors. Licensee MDPI, Basel, Switzerland. This article is an open access article distributed under the terms and conditions of the Creative Commons Attribution (CC BY) license (http://creativecommons.org/licenses/by/4.0/). 